Avrupa Bilim ve Teknoloji Dergisi

Özel Sayı, S. 216-223, Nisan 2020

(C) Telif hakkı EJOSAT'a aittir

Araștırma Makalesi
European Journal of Science and Technology

Special Issue, pp. 216-223, April 2020

Copyright C 2020 EJOSAT

Research Article

\title{
Uzayda Yerli Kaynaklar ile Yapı Malzemesi Üretimi*
}

\author{
Asena Karslıoğlu ${ }^{1 * *}$, Mehmet İnanç Onur² \\ ${ }^{1}$ Eskişehir Teknik Üniversitesi, Lisansüstü Eğitim Enstitüsü, Eskişehir, Türkiye (ORCID: 0000-0001-5178-4069) \\ 2 Eskişehir Teknik Üniversitesi, İnşaat Mühendisliği Bölümü, Eskişehir, Türkiye (ORCID: 0000-0002-2421-4471)
}

(Konferans Tarihi: 5-7 Mart 2020)

(DOI: 10.31590/ejosat.araconf27)

ATIF/REFERENCE: Karslığlu, A., \& Onur, M. İ. (2020). Uzayda Yerli Kaynaklar ile Yapı Malzemesi Üretimi. Avrupa Bilim ve Teknoloji Dergisi, (Özel Sayı), 216-223.

\section{$\ddot{O} z$}

İnşaat mühendisliği; insanlığın başından beri var olan, gelecekte de var olmaya devam edecek olan temel bir mühendisliktir. İnşaat mühendisleri olumsuz koşullara karşı mevcut malzeme ve tekniği kullanarak insanlığa hizmet ederler. İnsanoğlu gidebileceği her yere gider sözüyle birlikte araştırmacılar tarafından uzayda kullanılabilecek yapı malzemelerini üretme çalışmaları da uzun zamandır devam etmektedir. Üretilen yapı malzemelerinin sadece uzay ortamına (yüksek vakum, düşük yerçekimi, vb.) dayanıklı olması değil, aynı zamanda sürdürülebilir olması da gerekmektedir. Uzay inşaat mühendisliğinin temel amaçlarından birisi de uzaydaki yerel olanakları kullanarak yapı malzemesi üretmektir. Bu çalışmada, geçmiş Ay ve Mars regoliti simülasyonları karşılaştırılmıştır. Ülkemizde gerekli simülasyonları yapabilmek için uygun toprakların elde edilebileceği bölgeler belirlenmiştir. Ayrıca, üretilecek simülasyonların sürdürülebilir olması için gereklilikler çalışma sonunda vurgulanmıştır.

Anahtar Kelimeler: Regolit, Ay toprăğ, Mars toprağı, Simülasyon, Yapı malzemeleri.

\section{Production of Construction Materials with Local Resources in Space}

\begin{abstract}
Civil engineering is a fundamental engineering that has existed since the beginning of humanity and will continue to exist in the future. The civil engineers serve humanity against the negative conditions by using available materials and techniques. Researchers have been going on studying to produce construction materials that can be used in space for a long time with this word that people go everywhere they can go. The construction materials produced must not only be resistant to the environment of space (i.e. high vacuum, low gravity, etc.), but must also be sustainable. One of the main purposes of space civil engineering is to produce construction materials using local resources in space. In this study, past Lunar and Martian regolith simulations are compared. In order to make necessary simulations, the regions where the suitable soil can be obtained from in our country are determined. In addition, the requirements for sustainability of the produced simulations are emphasized at the end of the study.
\end{abstract}

Keywords: Regolith, Lunar soil, Martian soil, Simulations, Construction material.

\footnotetext{
${ }^{*}$ Bu makale International Conference on Access to Recent Advances in Engineering and Digitalization (ARACONF 2020) de sunulmuştur.

${ }^{* * *}$ Sorumlu Yazar: Eskişehir Teknik Üniversitesi, Lisansüstü Eğitim Enstitüsü, Eskişehir, Türkiye (ORCID: 0000-0001-5178-4069), asenakarslioglu@eskisehir.edu.tr
} 
European Journal of Science and Technology

\section{Giriş}

İnsanoğlunun varoluşundan itibaren en önemli ihtiyaçlarından biri de barınma olmuştur. İlk zamanlarda mağaralarda yaşamaya başlayan insanlar, daha sonra dünya üzerindeki yerel kaynakları kullanarak kendilerine barınaklar yapmaya başlamışlardır. Öncelikle çalı çırpı, göçebe hayatındayken ağaç ve keçe, yerleşik hayata geçtiklerinde ise ahşap, toprak ve doğal taş kullanarak çeşitli barınaklar inşa etmişlerdir. Özellikle yerleşik hayata geçişten sonra mimarinin gelişmesiyle, insanoğlu bulunduğu coğrafya ve kültürün de etkisi altında farklı yapıtlar ortaya koymuştur. Bu yapıtlar teknolojik ilerlemeye bağlı olarak geliştirilen farklı yapı malzemeleri kullanılarak inşa edilmiştir. Günümüzde kolay şekil verilebilmesi, ekonomik olması, üretiminin ve kullanımının kolay olması, ortama karşı dayanıklı olması, aktüalitesini ve popülerliğini kaybetmemesi sebebiyle beton, en çok tercih edilen yapı malzemesidir [Şimsek, 2012]. Betonun gelişimi öncelikle paleotik çağda kilin bağlayıcılık özelliğinin keşfedilmesinden sonra, neolitik çağda ateşin de keşfiyle birlikte alçı ve kirecin üretilmesiyle başlamıştır. Daha sonra Romalılar puzolan adlı malzemenin bağlayıcılık özelliğini fark edip, puzolanik malzemelerden ürettikleri betonu Pantheon Tapınağı gibi birçok yapıda kullanmıştır. İlk beton benzeri yapılarda geçirimsizliği sağlamak amacıyla silis kumu kullanıldı̆̆ı ve bu yapıların M.Ö. 6500 yıllarında Suriye'de yaşayan Nabataean halkı tarafından yapıldığı bilinmektedir. Günümüzde bağlayıcı olarak kullanılan Portland Çimentosunun mucidi ise duvar ustası olan İngiliz Joseph Aspdin'dir [Engin, 2017]. Çimentonun icadıyla günümüz geleneksel betonunun ana temelleri oluşmuştur. Geleneksel beton; bağlayıcı malzeme olarak çimento, hacim değişikliğini engellemek amaçlı iri agrega, kılcal boşlukları tıkamak için ince agrega, işlenebilirliği arttırmak ve çimentonun hidratasyonunu gerçekleştirmek için suyun belirlenen oranlarda homojen şekilde karıştıılmasıyla oluşan kompozit bir yapı malzemesidir. Gün geçtikçe beton üretimi artık insanların barınma ihtiyacının yanında farklı ihtiyaçlara ve durumlara göre de gelişmeye devam etmektedir. Örneğin soğuk bölgeler için hava sürükleyici beton, nükleer santraller için ağır beton, deniz yapılarının sülfattan ve tuzlardan korunması için düşük poroziteye sahip beton, depremselliğin olduğu yerlerde yüksek dayanım ve sünek beton, son zamanlarda ise maliyet ve sürdürülebilirlik için atıklar kullanılarak hazırlanan özel betonlar üretilmeye başlanmıştır. Özel betonların amaçlarından biri süneklik, durabilite, enerji tokluğu gibi özelliklerinin gelişmesini sağlamaktır [Şimsek, 2012]. Bu maksatla betona mineral ve kimyasal katkı maddelerinin, çeşitli fiberlerin eklenmesiyle ilgili çalışmalar yapılmıştır.

Shang vd. tarafından donma-çözülme çevrimlerinin göreceli dinamik esneklik modülü (RDME) ve C20, C25, C30, C40 ve C50 hava sürükleyici betonunun ağırlık kaybı üzerindeki etkileri araştırılmıştır. Hava sürükleyici betonun donma-çözülme dayanımının geleneksel betondan çok daha yüksek olduğu sonucuna varılmıştır [Shang ve ark, 2013]. Gupta vd. ince agregaların yerine atık kauçuk elyaf kullanılmasının betonun darbe dayanımı üzerindeki etkisi değerlendirilmiştir. Çalışma, atık kauçuk elyafının, betonun dayanım direncini ve esnekliğini arttırmak için sürdürülebilir bir malzeme olarak kullanılabileceğini göstermektedir. Çalışma aynı zamanda silis dumanının darbe direncini arttırdığını ve kauçuk elyaf betonun sünekliğini azalttığını göstermektedir [Gupta ve ark, 2015]. Xie vd. tarafından çelik elyaf takviyeli geri dönüştürülmüş agrega olarak kırıntı kauçuğu kullanılmış betonun basınç ve eğilme davranışları araştırılmıştır. Çelik liflerin betonda yeterince bulunması hem direnci hem de enerji emme kapasitesini arttırmaktadır [Xie ve ark, 2015]. Özetle, süregelen bu çalışmalarla betonun gelişmeye açık bir yapı malzemesi olduğu görülmektedir.

İnsanlar ilk çağlardan beri gökyüzünü oldukça ilgi çekici bulmuştur ve gökyüzüne olan merakla beraber astronomi çalışmaları başlamıştır. Başlangıçta, sadece günlük yaşamlarını düzenlemeye yardımcı olan bu çalışmalar gittikçe araştırmacıların gezegenler, asteroitler, yıldızlar vb. gibi gök cisimlerini yakından tanımak istemesine dönüşmüşsür. Uzay hakkında daha fazla bilgi edinmek istenildiği için 1950'li yıllardan beri uzaya araçlar gönderilmektedir. Dünyadaki kaynakların tüketilmesi, atıkların fazlalaşması, insan nüfusunun artması ve uzayda yapılan araştırma sonuçları; araştırmacılar yakın olması sebebiyle önce Ay'a ve daha sonra rengi ile bizleri etkileyen kızıl gezegen Mars’a koloniler kurmayı amaçlamaktadır. Bu durum ise insanlığın başlangıcından beri en temel ihtiyacımız olan barınmayı uzay ortamında nasıl gerçekleştireceğimiz sorusunu akıllara getirmektedir. Dünyada olduğu gibi Ay ve Mars'ta da barınma ihtiyacımız için yapılar inşa etmemiz ve bunun içinde yapı malzemeleri üretmemiz gerekmektedir. Kendine has esnekliği ve dayanıklılık özelliklerinden dolaylı beton, Ay ve Mars yapılarında ilk tercih edilecek yapı malzemesi olacaktır. Betonun üretilmesinde yerinde kaynak kullanımı ise çalışmalar içerisinde önemli bir yere sahiptir. Yerinde kaynak kullanımı (ISRU), Dünya'ya bağımlılı̆̆ en aza indirmek için uzay araştırmaları sırasında karşılaşılan yerli kaynakların toplanması ve işlenmesi olarak tanımlanmaktadır. Steinhoff'a göre, ISRU uzay keşif maliyetlerini 10 ila 50 kat arasında değişen bir şekilde azaltma potansiyeline sahiptir [Steinhoff, 1966].

ISRU'dan üretilen beton ve beton türevlerinin insan yerleşimi için uygunluğu uzay benzeri ortam atmosferinde (radrasyon, vakum, düşük yerçekimi, vb.) yıllardır incelenmektedir. Kanamori vd. 1 torr büyüklüğündeki vakuma maruz bırakılan geleneksel beton numunelerinde ilginç bir davranış olduğunu fark etmiş̧lerdir. Deneyde beton silindirler $1,3,7$ ve 28 gün boyunca suda kürlendikten sonra 2 gün ile 1 yıl arasında değişen bir süre boyunca vakuma maruz bırakılmıştır. 28 gün boyunca su ile işlem görmüş numunelerin, 1 yıl vakuma maruz kaldıktan sonra, su içinde kürlenen numunelerden daha yüksek basınç ve eğilme dayanımlarına sahip oldukları gözlenmiştir. Bu davranış, jel ve kılcal gözeneklerdeki suyun varlığından dolayı devam eden çimento hidrasyonuna bağlanmıştır [Kanamori ve ark, 1991]. Horiguchi vd. Portland çimentosundan hazırlanan beton ve harcın davranışını ay simülasyonundan hazırlananlar ile karşılaştırmıştır. 40x40x40 mm olan kübik numuneler kürlenmeye bırakılmış, sertleştikten sonra 10-4 torr büyüklüğündeki vakum koşullarını simüle etmek için kapalı bir odaya yerleştirilmiştir. Ay simülasyonundan hazırlanmış beton küplerin basınç dayanımı Portland çimentosundan yapılmış küplerde ölçülenden yaklaşık \%58 daha yüksek çıkmışıı [Horiguchi ve ark, 1998].

Uzay inşaatında hidrolik olmayan beton üretmek için, son zamanlarda bazı alternatifler araştıılmıştır. Polimer betonu geliştirmek için termoplastik ve/veya termoset polimerlerin kullanılması bir alternatif olabilir. Polimer beton karışımında, agregaları ve dolgu malzemelerini bağlamak için kullanılan polimerin eritilmesi gerekmektedir. Bu sebeple karışım genellikle ısıtılır veya UV 1şığına 
maruz bırakılmaktadır [Naser, 2019]. Lee vd. belirli bir polimer miktarının Dünya'dan ithal edilmesi gerektiğini varsayarak Ay'da termoplastik polimer içeren ay betonunun geliştirmişlerdir. Kütlece $\% 10$ polimer ve $\% 90$ ay toprağı karışımı, 50x50x50 mm'lik bir kübik kalıba dökülmüş, ortam taklit edilerek testler gerçekleştirilmiştir. Ay betonunun dayanımı bu şartlar altında 5 saat içinde yaklaşık 12.6-12.9 MPa ölçülmüştür. Böylece, yaşam alanı, iniş / firlatma rampası ve tesisleri kapsayan, bir altyapı oluşturmak için yeterli olan beton dayanımına ulaşılmıştır. Azami taşıma yükü göz önüne alındığında, Ay'a yapılan tek inişle yaklaşık 100 ton Ay betonu üretilebileceği sonucuna varılmıştır [Lee ve ark, 2015].

Ay ve Mars’ta yüksek miktarda kükürt bulunması da uzay yapılarında kükürt betonu kullanılabileceği araştırmalarına sebebiyet vermektedir. Erimiş kükürt çimento esaslı malzemeler ile karıştırılır, kükürt soğuduğunda, katılaşır ve kükürt betonu oluşur. Bu tip betonlar hidrasyon gerektirmezler ve birkaç gün içerisinde haftalarca sürebilen normal betondan farklı olarak dayanımlarını birkaç saat içinde kazanırlar [Naser, 2019]. Grugel vd. tarafından yapılan çalışma agregaya ek olarak JSC-1 ay simülasyonu ile Si02 tozu kullanılarak hazırlanan saf kükürtten üretilen iki set küçük kükürt beton numunesini değerlendirmektedir. Saf kükürt ve iki kükürtlü beton karışımı hazırlanmıştır ve 60 gün boyunca yaklaşık $20^{\circ} \mathrm{C}^{\prime} \mathrm{de} 5 \times 10^{-7}$ torr kapasiteli bir vakum ortamına yerleştirilmiştir. Numunelerin periyodik olarak tartılması, kükürtün buharlaşmasından dolayı sürekli bir kilo kaybını ortaya çıarmıştır [Grugel ve ark, 2008]. Wan vd. 21. yüzyılda uzay araştırmalarında önemli bir adımın Mars'a insan yerleşiminin olacağını söylemektedir. Mars'ın uzun süredir "kükürt bakımından zengin bir gezegen" kabulü ile simule edilmiş Mars toprağı ve erimiş kükürt içeren yeni bir yapı malzemesi geliştirilmiştir. Optimum karışım oranlarını elde etmek için farklı kükürt yüzdeleri araştırılmıştır. Mars betonu üretimi için en iyi karışım \%50 kükürt ve toplam agrega büyüklüğü $1 \mathrm{~mm}$ olan \%50 Mars toprak simülasyonudur. Dayanımın gelişimi, dayanım değişkenliği ve kırılma mekanizmalarını belirlemek için üç noktada eğilme, serbest basınç ve yarma deneyi yapılmıştır. Deney sonuçları, Mars Betonunun dayanımının, normal kum kullanan kükürt betonunun iki katına çıktığını göstermektedir. Ayrıca partikül büyüklüğü dağılımının, karışımın nihai kuvvetinde önemli bir rol oynadığı gösterilmiştir. Buna ek olarak, Mars toprağı metal bakımından zengin olduğu için, sülfatlar ve potansiyel olarak polisülfatlar da yüksek sıcaklıkta karıştırma sırasında oluştuğu ve bunun da yüksek dayanıma katkıda bulunduğu söylenebilir. Son olarak Mars betonu, çeşitli yükleme koşulları altında malzeme tepkisini modelleme konusunda mükemmel bir yetenek sergileyen Kafes Ayrık Parçacık Modeli (LDPM) ile simüle edilmiştir [Wan ve ark, 2016].

Geopolimer beton \%20-30'luk bir geopolimer bağlayıcıdan (uçucu kül, metakaolin vb. gibi) ve \%70-80'i kaba ve ince agregalardan oluşan, neredeyse sıfıra yakın su tüketimine, termal döngü ve donma-çözülmeye karşı yüksek dirence ve iyi vakum stabilitesine sahip bir beton çeşididir. Bu tip betonun dayanımı aynı zamanda geleneksel betonun basınç ve eğilme dayanımının iki-üç katıdır ve sadece 1-2 gün içerisinde tam dayanımını elde etmek için hızlandırılmış kürleme ile tasarlanabilmektedir [Naser, 2019]. Alexiadis vd. yerinde geopolimer beton üretmek için Ay simülasyonu JSC-1A ve Mars simülasyonu Mars-1A'nın potansiyelini araştırmıştır. Ay ve Mars simulasyonlu geopolimer beton numuneleri üzerinde basınç ve eğilme deneyleri yapılmıştır. Bu deneylerin sonucu, Ay geopolimer betonunun hem Mars geopolimer betonunu hem de geleneksel betonu geride bıraktığını göstermiştir. Mars geopolimer betonunun belirgin bir şekilde düşük basınç dayanımı, Mars geopolimer betonunun geliştirilmesinde kullanılan Mars-1A simulasyonlarının düşük reaktivitesine bağlanmıştır [Alexiadis ve ark, 2017].

Yapılan çalışmalar; hem Ay ve Mars kaynaklarının yerinde kullanımının (ISRU) ne kadar önemli olduğu hem de yapılan simülasyonların uzay yapılarında kullanılacak yapı malzemelerini geliştirmekteki önemini göstermektedir. Türkiye olarak yaklaşan uzay çağı için gerekli hazırlıkların yapılması gerekmektedir. Bu sebepten bu çalışmada, öncelikle gerçek Ay ve Mars regoliti ile literatürde verilmiş yapay regolitler sunulmuştur. Türkiye'de üretilecek yapay regolitler için kaynak araştırması yapılmıştır. Gerekli testler ile işleme teknolojileri de belirtilmiş ve ülkemizde bu çalışmalar için öncü kaynak oluşturulması hedeflenmiştir.

\section{Materyal ve Çalışma}

\subsection{Uzay Ortamı}

Uzay ortamı; düşük yerçekimi, yüksek vakum, ani yüksek ve düşük sıcaklıklar, güçlü radyasyon ve plazma ile dolu karmaşık bir ortamdır [14]. Ay ve Mars'ın düşük yer çekimi ile aşırı sıcaklık döngülerinin düşük atmosferik basınca neden olması ve radyas yona karşı zayıf kalkan gibi olması atmosferi olumsuz etkilemektedir. Ay ve Mars'taki yerçekimi sırasıyla Dünya'dakinin 1/6'sı ve 3/8'i kadardır. Dünya'daki atmosferik basınç ise $101.2 \mathrm{kPa}$ olmasına rağmen Ay'da $3 \times 10^{-13} \mathrm{kPa}$, Mars'ta $7 \times 10^{-1} \mathrm{kPa}$ değerindedir. Yüzey sıcaklıkları arasındaki farklar ise Ay'da $-171^{\circ} \mathrm{C}$ ile $111^{\circ} \mathrm{C}$, Mars'ta $-143^{\circ} \mathrm{C}$ ile $35^{\circ} \mathrm{C}$ arasında değişim gösterebilmektedir. Bu sıcaklık değişimleri termal genleşmelere ve büzülmelere de sebebiyet vermektedir. Mars'ın zayıf atmosferi nedeniyle, kuvvetli rüzgâr oluşumu yaygın değildir ve sadece belirli yerlerde maksimum $100 \mathrm{~km} /$ saat hıza ulaşabilir. Ay ve Mars ortamının çok tozlu olduğu ve radyasyonun çok yüksek olduğu vurgulanmaktadır. Radyasyon seviyesi Ay'da 380 mSv, Mars'ta 100 mSv civarındadır [Mueller, 2017].

\subsection{Ay ve Mars Regoliti}

Uzayda yerel kaynak olarak kullanılabilecek olan malzeme, kalınlığını onlarca metreye kadar değişen büyük parçaların zaman içinde güneş ve galaktik ışınlar ile fiziksel olarak küçük parçalara ayrılmasıyla oluşan regolittir. Gerçekte regolitin bilinen anlamdaki toprakla benzeşmemesinin nedeni organik bileşimleri içermemesidir [Kuvvet, 2010]. Toprak terimi bazen regolit ile eş anlamlı olarak kullanılsa da bu terim aslında Ay ve Mars yüzeyini kaplayan malzemelerin konsolide olmayan parçalarının daha ince kesimlerini $(<10 \mathrm{~mm}$ çapında) ifade etmektedir [Naser, 2019]. 
Ay'ın Dünya'ya daha yakın ve uydusu olması sebebiyle Ay regoliti hakkında daha fazla bilgi bulunmaktadır. Regolitin dane çapı yaklaşık $100 \mu \mathrm{m}$ civarındadır, bu durumda bize regolitin toz gibi bir malzeme olduğunu göstermektedir. Yapışma durumu ise oldukça fazladır, 1slak plaj kumuna benzetilmektedir. Boşluk oranı $\% 45$, yüzey alanı $0.5 \mathrm{~m}^{2} / \mathrm{g}$, kohezyon $0.1-1 \mathrm{kN} / \mathrm{m}^{2}$, sürtünme açısı $=30-50^{0}$ ve zemin modülü $1000 \mathrm{kN} / \mathrm{m}^{2} / \mathrm{m}^{\prime}$ dir.

\subsection{Ay ve Mars Simülasyonları}

Önceleri yapı malzemelerinin Dünya'da üretildikten sonra Ay veya Mars'a taşınabileceği düşünülmekteydi fakat bunun maliyetinin çok yüksek olması sebebiyle araştırmacılar uzaydaki yerel kaynaklara yönelmiştir. Benzer şekilde, araştırmalar için Ay ve Mars'tan toprak getirmenin uzun sürmesi ve yeterli miktarda getirilmesinin imkânsız olması simülasyonlara yönelimi doğurmuş̧ur. Tablo 1'de bugüne kadar yapılmış kailteli Ay ve Mars simülasyonları görülmektedir.

Tablo 1. Ay ve Mars simülasyonlarının adlarl [Database, 2014]

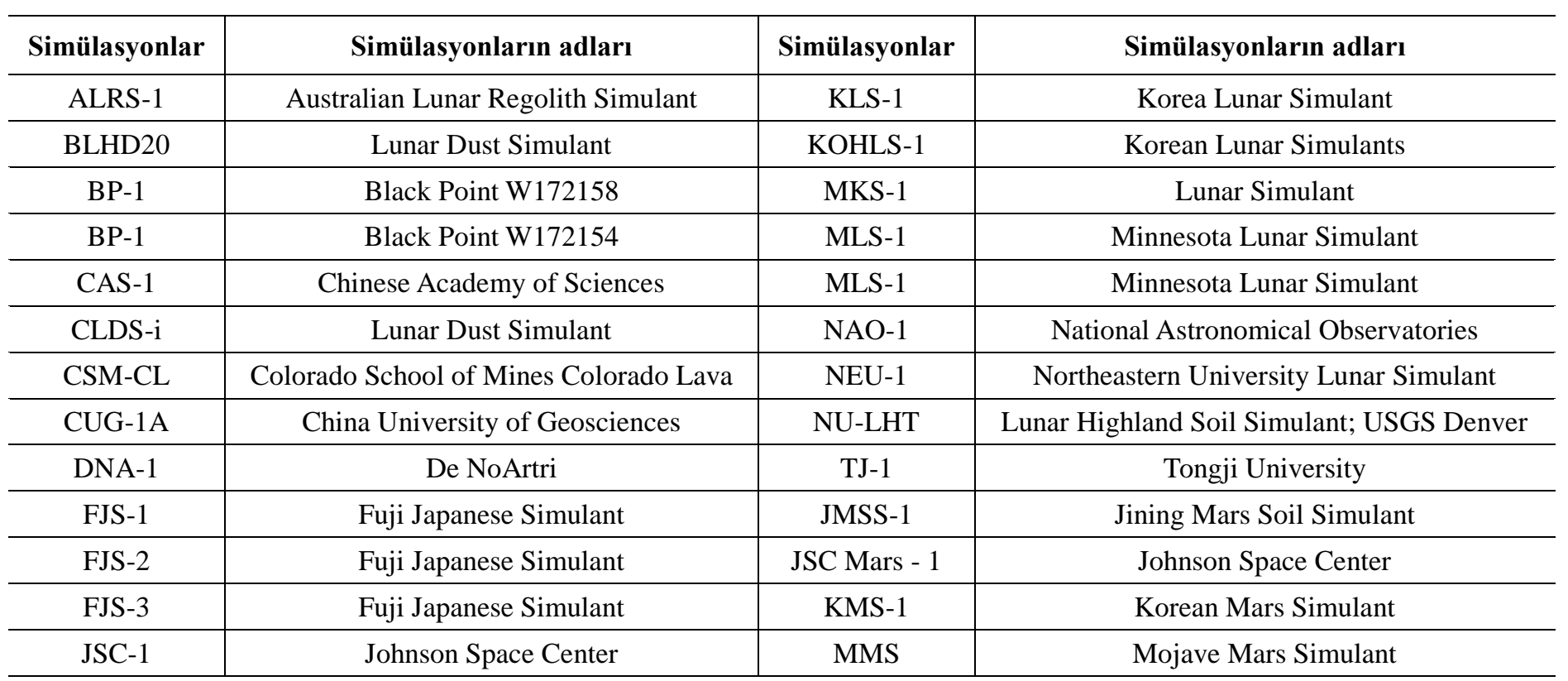

Tablo 2'de Ay simülasyonlarının Ay'dan getirilmiş olan Lunar 14163 numunesi ve Apollo 16 numunesi ile Mars simülasyonlarının Mars’tan getirilmiş olan regolit numunesi ile karşılaştırılması gözükmektedir. Mars simülasyonlarının çok az olması ve Mars regolitinde \% 4,9 bulunan kükürt trioksit $\left(\mathrm{SO}_{3}\right)$ bileşeninin yapılmış hiçbir simülasyonda bulunmaması da dikkat çeken noktalardan birisidir.

\section{Araștırma Sonuçları ve Tartışma}

\subsection{Kullanılabilecek Topraklar}

Geçmiş simülasyonlar incelendiğinde volkanizma kökenli toprakların Ay ve Mars simülasyonu için en uygun topraklar olduğu görülmektedir. Ülkemizde yapılan jeolojik araştırmalara göre farklı bölgelerde gerekli jeolojik özelliklere sahip topraklar bulunduğu tespit edilmiştir. Şekil 1'de harita üzerinde işaretlenen bu bölgelerin genel kimyasal özelikleri bakımından yeterli olduğu ancak bazı elementler gerektiği öngörülmektedir. İşaretlenen bölgelerden alınacak numunelerin kimyasal bileşimleri belirlendikten sonra eksik olan elementler uygun şekilde karışıma eklenmeli ve simulasyonlar hazırlanmalıdır. Özellikle Malatya gibi kükürt bazlı toprakların olduğu bölgelerden alınacak numuneler karıştırılarak Mars regoliti simülasyonu üretilebilecektir.

Toklu vd. yaptıkları çalışmada, Türkiye'de Ay simülasyonu üretmek için bir adım atarak simülasyonda kullanmak için Kula tepeleri bölgesinde 8 farklı yerden 8 farklı örnek toplamışlardır. Toplanan örneklerin XRF analizi yapılmıştır ancak bazı elementlerin bu örneklerde bulunmamasından kaynaklı, Ay simülasyonu yapılamamıştır. Eksik elementleri içeren numunelerin başka bir yerden toplanması veya bu elementleri içeren bileşiklerin karışıma eklenmesi gerektiği söylenmiştir [Toklu ve ark, 2017]. 


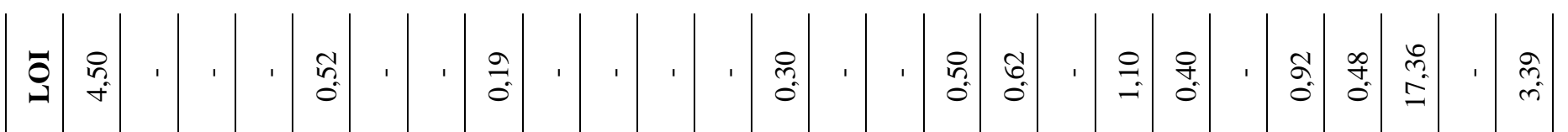

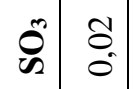

\begin{tabular}{ccc}
$\vec{m}$ & \multirow{0}{*}{} & 0 \\
0 & 0 & 0 \\
0
\end{tabular}

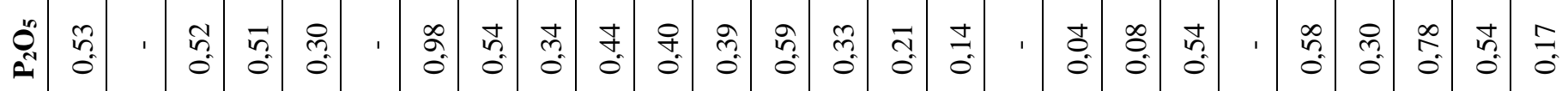

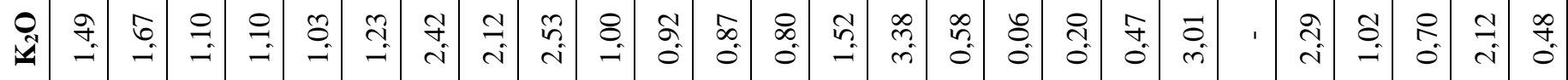

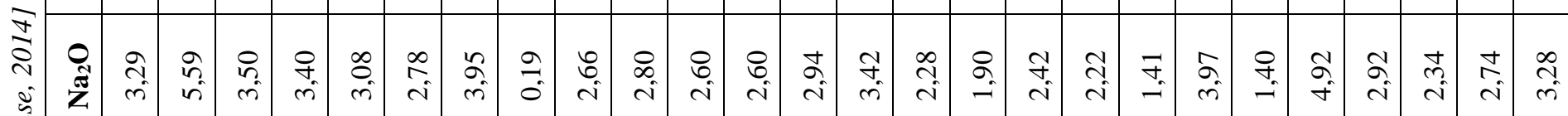

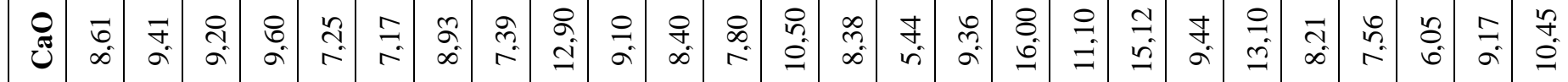

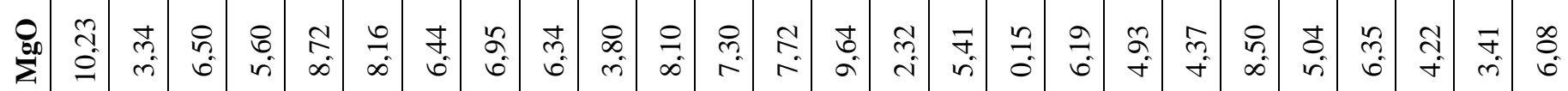

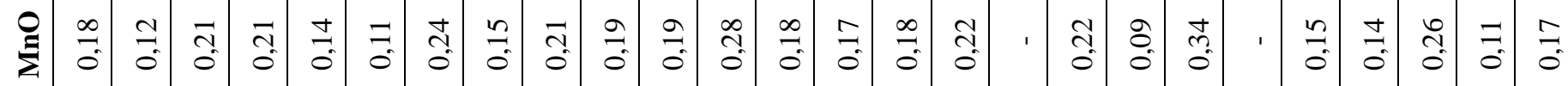

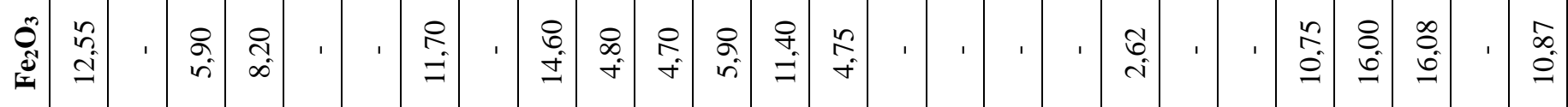

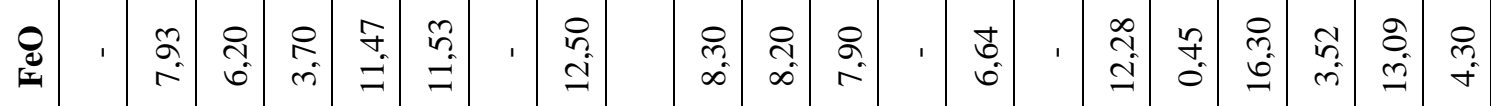

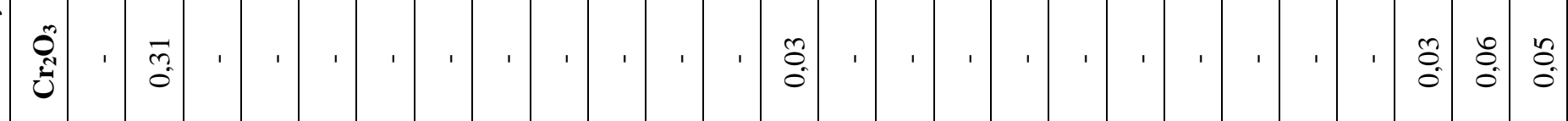

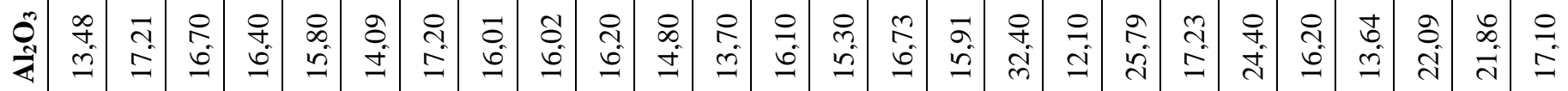

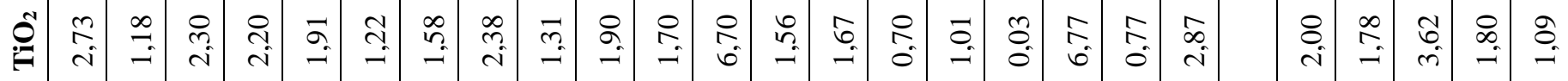

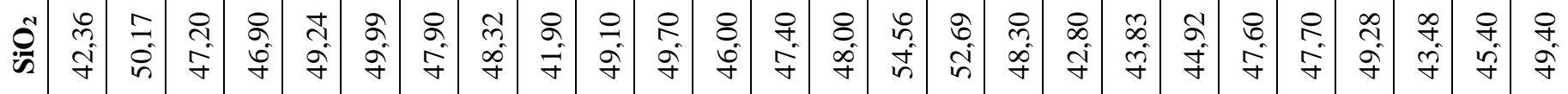

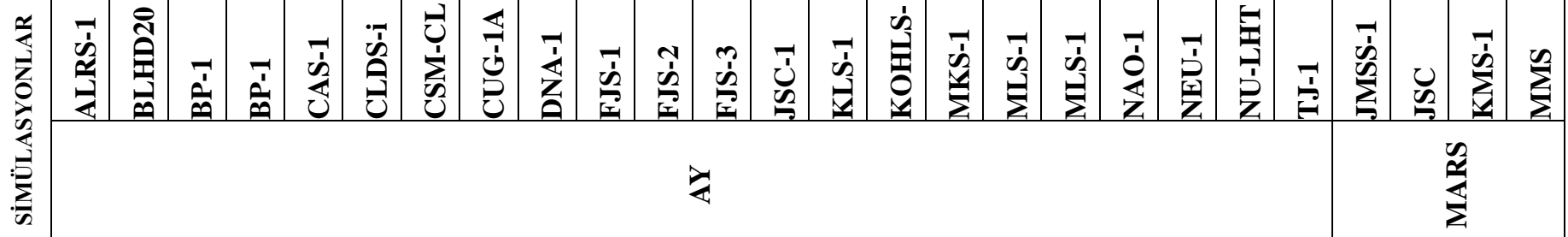




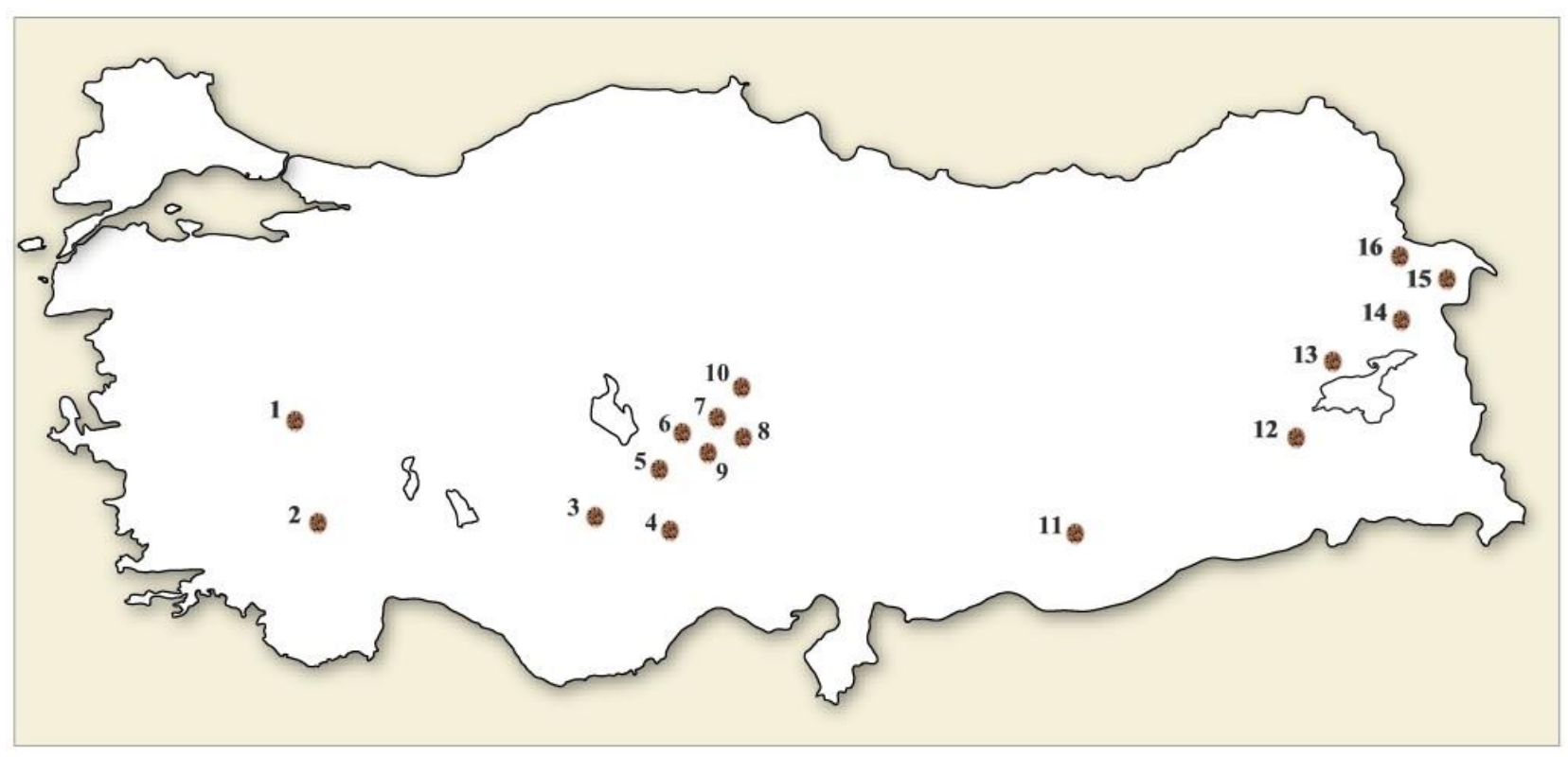

Şekil 1. Türkiye'de Ay ve Mars regoliti simülasyonunda kullanılabilecek topraklar

Şekil 1'de görülen noktalar; (1) Kula tepeleri, (2) Salda Gölü, (3) Karadağ, (4) Karapınar düzlüğü, (5) Karacadağ, (6) Hasan Dağı, (7) Melendiz Dağı, (8) Göllü Dağ, (9) Acıgöl, (10) Erciyes Dağı, (11) Karacadağ (Şanlıurfa), (12) Nemrut Dağı, (13) Süphan Da ğı, (14) Tendürek Dağı, (15) Küçük Ağrı Dağı ve (16) Büyük Ağrı Dağı'nı belirtmektedir. Fark edildiği üzere kullanılabilecek volkanik topraklar İç Anadolu Bölgesi'nde toplanmış şekildedir.

\section{2. Üretilebilecek Yapı Malzemeleri}

Yerel kaynak olan regolit kullanılarak çeşitli yapı malzemeleri üretilebilmektedir. Beton ve beton benzeri malzemeler, metaller, alaşımlar, metal köpükler ve kompozitler üretilebilecek yapı malzemelerine örnektir.

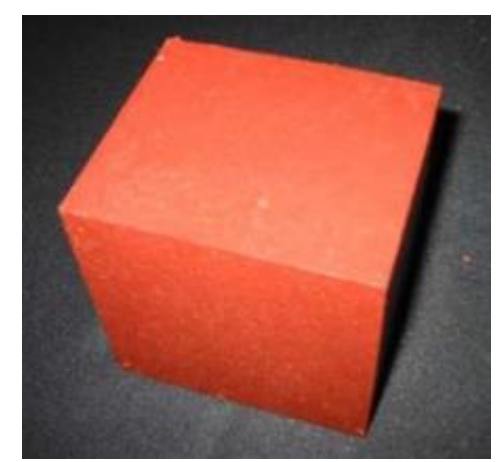

Şekil 2. Mars tuğlası [Ishikawa, 2009]

Regolitin kimyasal içeriğinin, uçucu kül, yüksek fırın cürufu ve portland çimentosu arasında Tablo 3'deki gibi bir karşılaştırma yapıldığında regolit bileşiminin bu malzemelere ne kadar yakın olduğu görülmektedir. Ay ve Mars yüzeylerinde bol miktarda regolit bulunduğundan, bu kaynağın betonun geliştirilmesi için ana bileşeni oluşturabileceği düşünülmektedir. Her ne kadar çağdaş uzaktan algılama çabaları, Ay ve Mars kutuplarına yakın su rezervlerinin bulunma olasılığını göstermiş olmasına rağmen, bazı soru işaretleri bulunmaktadır. Suların kalitesi ve yapı malzemeleri üzerindeki etkileri bilinmemektir. Bundan kaynaklı susuz beton olarak bilinen polimer beton, kükürtlü beton, geopolimer beton ve çok amaçlı betonlara yönelinmiştir.

\subsection{Deneyler}

Uzay yapıları için üretilecek olan beton ve benzeri türevlerinin uzay ortamı koşullarına tabi tutularak deneylerin gerçekleştirilmesi gerekmektedir. Beton radyasyon, yüksek vakum veya düşük yerçekimi gibi ortamlarda bekletildikten sonra basınç dayanımı belirlemek amacıyla; beton basınç deneyi, eğilme dayanımı için 3 noktada veya 4 noktada eğilme deneyi yapılmalıdır. Numunenin mikro yapısı da büyük önem arz ettiğinden taramalı elektron mikroskobunda incelenmelidir. 
Tablo 3. Regolit ve puzolan malzemelerin kimyasal içeriklerinin karşılaş̧tırlması [Erdoğan, 2015, Database, 2014]

\begin{tabular}{c|c|c|c|c|c|c|c}
\hline Bileşenler & $\begin{array}{c}\text { Portland } \\
\text { Çimentosu }\end{array}$ & $\begin{array}{c}\text { F Sınıfi } \\
\text { Uçucu Kül }\end{array}$ & $\begin{array}{c}\text { C Sinıfi } \\
\text { Uçucu Kül }\end{array}$ & $\begin{array}{c}\text { Yüksek } \\
\text { Firın } \\
\text { Cürufu }\end{array}$ & $\begin{array}{c}\text { Ay Regoliti } \\
\text { Lunar14163 } \\
\text { (karanlı bölge) }\end{array}$ & $\begin{array}{c}\text { Ay Regoliti } \\
\text { Apollo16 } \\
\text { (dağlı bölge) }\end{array}$ & $\begin{array}{c}\text { Mars Regoliti } \\
\text { Ortalaması }\end{array}$ \\
\hline $\mathbf{S i O}_{2}$ & 20,7 & $43,6-64,4$ & $23,1-50,5$ & $34,0-36,0$ & 47,3 & 45,0 & 46,5 \\
\hline $\mathbf{T i O}_{2}$ & - & - & - & - & 1,6 & 0,5 & 0,9 \\
\hline $\mathbf{A l}_{2} \mathbf{O}_{3}$ & 6,0 & $19,6-30,1$ & $13,3-21,3$ & $13,0-19,0$ & 17,8 & 27,3 & 10,5 \\
\hline $\mathbf{C r}_{2} \mathbf{O}_{3}$ & - & - & - & - & 0,2 & - & 0,4 \\
\hline $\mathbf{F e O}$ & - & - & - & - & 10,5 & 5,1 & 12,2 \\
\hline $\mathbf{F e}_{2} \mathbf{O}_{3}$ & 2,4 & $3,8-23,9$ & $3,7-22,5$ & $0,3-2,5$ & - & - & 4,2 \\
\hline $\mathbf{M n O}$ & - & - & - & $1,0-2,5$ & 0,1 & 0,3 & 0,3 \\
\hline $\mathbf{M g O}$ & 2,6 & $0,9-1,7$ & $1,5-7,5$ & $3,5-7,0$ & 9,6 & 5,7 & 8,9 \\
\hline $\mathbf{C a O}$ & 63,6 & $0,7-6,7$ & $11,5-29,0$ & $34,0-41,0$ & 11,4 & 15,7 & 6,3 \\
\hline $\mathbf{N a}_{2} \mathbf{O}$ & 0,1 & $0,0-2,8$ & $0,4-1,9$ & - & 0,7 & 0,2 & 3,0 \\
\hline $\mathbf{K}_{2} \mathbf{O}$ & 0,9 & - & - & - & 0,6 & 0,1 & 0,4 \\
\hline $\mathbf{P}_{2} \mathbf{O}_{5}$ & - & - & - & - & - & 0,1 & 0,8 \\
\hline $\mathbf{S O}_{3}$ & 2,1 & - & - & - & - & - & 4,9 \\
\hline $\mathbf{C l}$ & 0,1 & - & - & - & - & - & 0,6 \\
\hline
\end{tabular}

\section{4. İşleme Teknolojisi}

Ay ve Mars'ın zorlu şartları göz önüne alındığında, inşaat malzemelerini üretmek için yerinde kaynakları araştırmak, toplamak ve işlemek için robotik, özerk işleme ve inşaat sistemleri geliştirmek de çok önemlidir. Uzayda uygulanma potansiyeline sahip özerk işleme ve yapım tekniği, eklemeli baskıdır. Eklemeli baskı, hızlı ve hassas yapı üretmek için yapı malzemelerini biriktiren robotik bir işlemdir. Geleneksel olarak eklemeli baskı, sabit geometrili yapıların üretilmesini içermektedir [Naser, 2019]. BP-1 simülasyonuna ağırlıkça \% 30 "Jetty Park" sahil kumu ve standart beyaz yapı kumunun eklendiği örnekler literatürde bulunmaktadır. Şekil 3' de üretilen örnek yapılar verilmiştir.

Eklemeli baskı geçmiş birkaç regolit simülasyonu işleminde gerçekleştirilmiştir [Mueller, 2017]:

> BP-1, Ay Regolit Bazalt Simülasyonu - (NASA KSC)

$>$ JSC-1A, Ay Karanlık Bölge Simülasyonu - (NASA Johnson Uzay Merkezi JSC)

$>$ NU-LHT-2M, Ay Dağlık Bölge Tipi Simülasyonu - (NASA USGS)
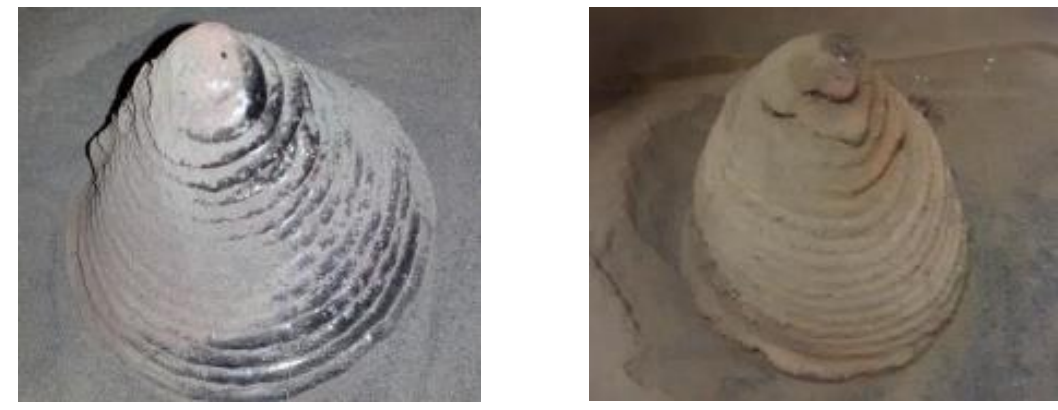

Şekil 3. Swamp Works 3D Regolith Construction işlemi tarafından oluşturulan küçük çaplı yapılar [Mueller, 2017]

\section{Sonuç}

İş̧aat mühendisliği genel olarak insanlık tarihinin en eski mesleklerinden biri olmasının yanında gelecekte de var olmayı sürdürerek insanlığa hizmet edecektir. İnşaat mühendisliği günümüzde uzay çalışmalarında da yer edinmeye başlamıştır. Dünya dışında bir yaşam ortamı arayışı içinde olan araştırmacılar, uzun yıllardır Ay'ın ve Mars'ın yaşama elverişli koşullarına sahip olmasıyla birlikte insanlığın nüfus yoğunluğunu kaldırabilecek gök cisimleri olduklarını savunmaktadır. Tüm inşaat malzemelerini Dünya'dan inanılmaz bir maliyetle taşımak yerine, yerel kaynak regolitini kullanmak mükemmel bir alternatif olacaktır.

Türkiye'de uzay çalışmaları uzun süredir sadece uydu ve iletişim araçları üzerine kurulmuş olmasına rağmen 2023 hedefleri doğrultusunda uzaya astronot gönderilmek istenmesiyle birlikte, Türkiye gerçek anlamda uzay çalışmalarına başlamaktadır. Dolayısıyla; ileriye dönük olarak aşağıdaki konuların araştırılması gerekmektedir:

> Ay veya Mars habitatlarını gerçekleştirebilecek yüksek kalitede simülasyonlar yapmak,

$>$ Uzay ortamında kolayca kullanılabilecek yeni bir inşaat malzemesi geliştirmek,

$>$ Uzayda bulunan yerel kaynakları kullanarak inşaat malzemelerini üretmek,

> Uzaydaki yapıları inşa etmek için kullanılabilecek yeni bir işleme teknolojisi geliştirmek. 


\section{Kaynakça}

Şimşek, O., Beton ve Beton Teknolojisi Dördüncü Baskı., Seçkin Yayıncılık, Ankara, 2012.

Engin, Y., Çimento ve Beton Tarihi. Beton Kalıp İskele Teknolojileri Dergisi, 2017.

Shang, H. S., \& Yi, T. H. (2013). Freeze-thaw durability of air-entrained concrete. The Scientific World Journal, 2013.

Gupta, T., Sharma, R. K., \& Chaudhary, S. (2015). Impact resistance of concrete containing waste rubber fiber and silica fume. International Journal of Impact Engineering, 83, 76-87.

Xie, J. H., Guo, Y. C., Liu, L. S., \& Xie, Z. H. (2015). Compressive and flexural behaviours of a new steel-fibre-reinforced recycled aggregate concrete with crumb rubber. Construction and Building materials, 79, 263-272.

STEINHOFF, E. A. (1966). The Use of Mars and Phobos to Advance Interplanetary Flight. In Advances in Space Science and Technology (Vol. 8, pp. 347-383). Elsevier.

Kanamori, H., Matsumoto, S., \& Ishikawad, N. (1991). Long-term properties of mortar exposed to a vacuum. Special Publication, $125,57-70$.

Horiguchi, T., Saeki, N., Yoneda, T., Hoshi, T., \& Lin, T. D. (1998). Behavior of simulated lunar cement mortar in vacuum environment. In Space 98 (pp. 571-576).

Naser, M. Z. (2019). Extraterrestrial construction materials. Progress in Materials Science, 100577.

Lee, T. S., Lee, J., \& Ann, K. Y. (2015). Manufacture of polymeric concrete on the Moon. Acta Astronautica, 114, 60-64.

Grugel, R. N., \& Toutanji, H. (2008). Sulfur "concrete" for lunar applications-Sublimation concerns. Advances in Space Research, 41(1), 103-112.

Wan, L., Wendner, R., \& Cusatis, G. (2016). A novel material for in situ construction on Mars: experiments and numerical simulations. Construction and Building Materials, 120, 222-231.

Alexiadis, A., Alberini, F., \& Meyer, M. E. (2017). Geopolymers from lunar and Martian soil simulants. Advances in Space Research, $59(1), 490-495$

Chen, J., Ding, N., Li, Z., \& Wang, W. (2016). Organic polymer materials in the space environment. Progress in Aerospace Sciences, $83,37-56$.

Mueller, R. P. (2017). Construction with Regolith.

Kuvvet, M., Regolitin kullanım alanları, Ay’da ve Mars’ta regolitin yapı malzemesi olarak kullanımı, regolitten başka elementlerin ve maddelerin çıkarımı. Hava Harp Okulu Havacılık Ve Uzay Teknolojileri Enstitüsü, İstanbul, 2010.

Erdoğan, T. Y., Beton, Beşinci Baskı, ODTÜ yayıncılık, Ankara, 2015.

Center of Lunar Astreoid Surface Science. Ay ve Mars simülasyonlarının içerikleri. 2014. [Online]. Available: https://sciences.ucf.edu/class/planetary-simulant-database/ .

Toklu, Y. C., Çerçevik, A. E., Kandemir, S. Y., \& Yayli, M. O. (2017, June). Production of lunar soil simulant in Turkey. In 2017 8th International Conference on Recent Advances in Space Technologies (RAST) (pp. 1-5). IEEE.

Ishikawa, Y. (2009). Utilization of Regolith for Manufacturing Construction Material on Mars. In Mars (pp. 543-550). Springer, Berlin, Heidelberg. 